\title{
A new 3-D jerk chaotic system with two cubic nonlinearities and its adaptive backstepping control
}

\author{
SUNDARAPANDIAN VAIDYANATHAN
}

\begin{abstract}
This paper presents a new seven-term 3-D jerk chaotic system with two cubic nonlinearities. The phase portraits of the novel jerk chaotic system are displayed and the qualitative properties of the jerk system are described. The novel jerk chaotic system has a unique equilibrium at the origin, which is a saddle-focus and unstable. The Lyapunov exponents of the novel jerk chaotic system are obtained as $L_{1}=0.2974, L_{2}=0$ and $L_{3}=-3.8974$. Since the sum of the Lyapunov exponents of the jerk chaotic system is negative, we conclude that the chaotic system is dissipative. The Kaplan-Yorke dimension of the new jerk chaotic system is found as $D_{K Y}=2.0763$. Next, an adaptive backstepping controller is designed to globally stabilize the new jerk chaotic system with unknown parameters. Moreover, an adaptive backstepping controller is also designed to achieve global chaos synchronization of the identical jerk chaotic systems with unknown parameters. The backstepping control method is a recursive procedure that links the choice of a Lyapunov function with the design of a controller and guarantees global asymptotic stability of strict feedback systems. MATLAB simulations are shown to illustrate all the main results derived in this work.
\end{abstract}

Key words: chaos, chaotic systems, jerk systems, chaos control, adaptive control, backstepping control, synchronization.

\section{Introduction}

Modeling and applications of chaotic systems are active research areas in the literature $[1,2,3]$. The first famous chaotic system was discovered by Lorenz, when he was designing a weather model in 1963 [4]. Some well-known chaotic systems are Chen system [5], Lü system [6], Cai system [7], Tigan system [8], Sprott systems [9], etc.

Some well-known paradigms of 3-D chaotic systems are Arneodo system [10], Hénon-Heiles system [12], Lü-Chen system [13], Liu system [14], etc. Many new chaotic systems have been also discovered like Li system [15], Sundarapandian systems [16, 17], Vaidyanathan systems $[18,19,20,21,22,23,24,25,26,27,28,29,30$, $31,32,33$, Pehlivan system [34], Tacha system [35], Jafari system [36], Sampath system [37], Pham systems [38, 39, 40, 41, 42, 43, 44], Volos system [45], Akif system [46], etc.

The author is with Research and Development Centre, Vel Tech University, Avadi, Chennai-600062, Tamil Nadu, India. E-mail: sundarvtu@gmail.com

Received 18.11.2016. 
Chaos theory has applications in several fields of science and engineering such as oscillators $[47,48,49,50,51,52,53,54,55]$, dynamos [56, 57, 58, 59], Tokamak systems [60, 61], chemical reactions [62, 63, 64, 65, 66, 67, 68, 69, 70, 71], neural networks [72, 73, 74, 75, 76, 77], neurology [78, 79, 80, 81, 82, 83], biology [84, 85, 86, 87, 88, 89, 90, 91, 92], electrical circuits [93, 94, 95], induction motors [96], cryptosystems [97, 98], memristors [99, 100, 101], random bit generator [102], etc.

In classical mechanics, a jerk system is expressed by an explicit third order differential equation describing the time evolution of a single scalar variable $x$ according to the dynamics

$$
\frac{d^{3} x}{d t^{3}}=f\left(\frac{d^{2} x}{d t^{2}}, \frac{d x}{d t}, x\right)
$$

A particularly simple example of a jerk system is the famous Coullet system [103] given by

$$
\frac{d^{3} x}{d t^{3}}+a \frac{d^{2} x}{d t^{2}}+\frac{d x}{d t}=g(x)
$$

where $g(x)$ is a nonlinear function such as $g(x)=b\left(x^{2}-1\right)$. The Coullet system (2) exhibits chaos for $a=0.6$ and $b=0.58$.

A classical example of a cubic dissipative jerk chaotic flow was found by Sprott [104]. In this research work, we modify the dynamics of the jerk system in [104] by introducing two linear terms and taking different set values for the system parameters. Thus, we obtain a novel chaotic jerk system with two cubic nonlinearities.

In most of the synchronization approaches, the master-slave or drive-response formalism is used. If a particular chaotic system is called the master or drive system and another chaotic system is called the slave or response system, then the idea of synchronization is to use the output of the master system to control the response of the slave system so that the slave system tracks the output of the master system asymptotically $[105,106,107,108]$.

In the chaos literature, an impressive variety of techniques have been proposed for chaos synchronization such as active control method [109, 110, 111, 112, 113, 114, 115], adaptive control method [116, 117, 118, 119, 120, 121, 122, 123, 124, 125, 126, 127], backstepping control method [128, 129, 130, 131, 132, 133, 134, 135], sliding mode control method [136, 137, 138, 139, 140, 141, 142, 143, 144], etc.

All the main adaptive backstepping control results in this paper are proved using Lyapunov stability theory [145]. MATLAB simulations are depicted to illustrate the phase portraits of the novel jerk chaotic system, adaptive stabilization and synchronization results for the novel 3-D jerk chaotic system.

This research paper is organized as follows. Section 2 contains the dynamics and phase portraits of the novel chaotic jerk system. Section 3 details the qualitative properties of the novel chaotic jerk system. In Section 4, we apply adaptive backstepping control method to design an adaptive feedback control law that stabilizes the states of the novel jerk system. 
In Section 5, we apply adaptive backstepping control method to design an adaptive feedback control law that achieves complete and exponential synchronization of the states of identical novel chaotic jerk systems. Finally, Section 6 contains a summary of the main results obtained in this work.

\section{A new jerk chaotic system}

A classical example of a cubic dissipative jerk chaotic flow was found by Sprott [104] and described by the third-order differential equation

$$
\dddot{x}=-a \ddot{x}+x \dot{x}^{2}-x^{3} \quad(\text { with } a=3.6)
$$

In system form, Sprott's differential equation (3) corresponds to the jerk system

$$
\left\{\begin{array}{l}
\dot{x}_{1}=x_{2} \\
\dot{x}_{2}=x_{3} \\
\dot{x}_{3}=-a x_{3}+x_{1} x_{2}^{2}-x_{1}^{3}
\end{array}\right.
$$

where $a=3.6$ yields a chaotic attractor.

Using Wolf's algorithm [146], the Lyapunov exponents of the Sprott system (4) for $a=3.6$ are numerically obtained as

$$
L_{1}=0.1360, L_{2}=0, L_{3}=-3.7367
$$

From (5), we see that the Maximal Lyapunov Exponent (MLE) of the Sprott system (4) is $L_{1}=0.1360$. Since $L_{1}>0$, the Sprott system (4) is chaotic.

The Kaplan-Yorke dimension of a chaotic system of order $n$ is defined as

$$
D_{K Y}=j+\frac{L_{1}+L_{2}+\cdots+L_{j}}{\left|L_{j+1}\right|}
$$

where $L_{1} \geqslant L_{2} \geqslant \cdots \geqslant L_{n}$ are the $n$ Lyapunov exponents of the chaotic system and $j$ is the largest integer for which $L_{1}+L_{2}+\cdots+L_{j} \geqslant 0$. Thus, the Kaplan-Yorke dimension of the Sprott jerk system (4) is calculated as

$$
D_{K Y}=2+\frac{L_{1}+L_{2}}{\left|L_{3}\right|}=2.0364
$$

In this work, we propose a new jerk chaotic system, which is obtained by adding two linear systems $-b x$ and $c \dot{x}$, where $b, c>0$, to the Sprott's jerk function in the ODE (3). Thus, our new jerk chaotic flow is described by the third order ODE

$$
\dddot{x}=-a \ddot{x}+x \dot{x}^{2}-x^{3}-b x+c \dot{x}
$$


In system form, the third order ODE (8) corresponds to the jerk system

$$
\left\{\begin{array}{l}
\dot{x}_{1}=x_{2} \\
\dot{x}_{2}=x_{3} \\
\dot{x}_{3}=-a x_{3}-b x_{1}+c x_{2}+x_{1} x_{2}^{2}-x_{1}^{3}
\end{array}\right.
$$

where $a, b$ and $c$ are positive parameters.

In this paper, we shall show that the system (9) is chaotic when the parameters $a$ and $b$ take the values

$$
a=3.6, \quad b=1.3, c=0.1
$$

Using Wolf's algorithm [146], the Lyapunov exponents of the novel system (9) for the parameter values (10) are numerically obtained as

$$
L_{1}=0.2974, L_{2}=0, L_{3}=-3.8974
$$

From (11), we see that the Maximal Lyapunov Exponent (MLE) of the novel system (9) is $L_{1}=0.2974$. Since $L_{1}>0$, the novel system (9) is chaotic. Moreover, we also note that the MLE of the novel jerk system (9) is greater than the MLE of the Sprott jerk system (4). Also, the Kaplan-Yorke dimension of the novel jerk system (9) is calculated as

$$
D_{K Y}=2+\frac{L_{1}+L_{2}}{\left|L_{3}\right|}=2.0763,
$$

which is greater than the Kaplan-Yorke dimension of the Sprott jerk system (4).

For numerical simulations, we take the initial conditions of the system (9) as

$$
x_{1}(0)=0.5, x_{2}(0)=0.5, \quad x_{3}(0)=0.5
$$

The initial conditions in (13) have been chosen arbitrarily for the sake of simulations. For other initial conditions in $\mathbf{R}^{3}$ also, the system (9) is chaotic with a similar strange attractor.

Figure 1 depicts the chaotic attractor of the novel jerk system (9) in 3-D view. Figures 2-4 depict the 2-D projection of the strange chaotic attractor of the novel jerk chaotic system (9) on $\left(x_{1}, x_{2}\right),\left(x_{2}, x_{3}\right)$ and $\left(x_{3}, x_{1}\right)$ planes, is shown, respectively. 


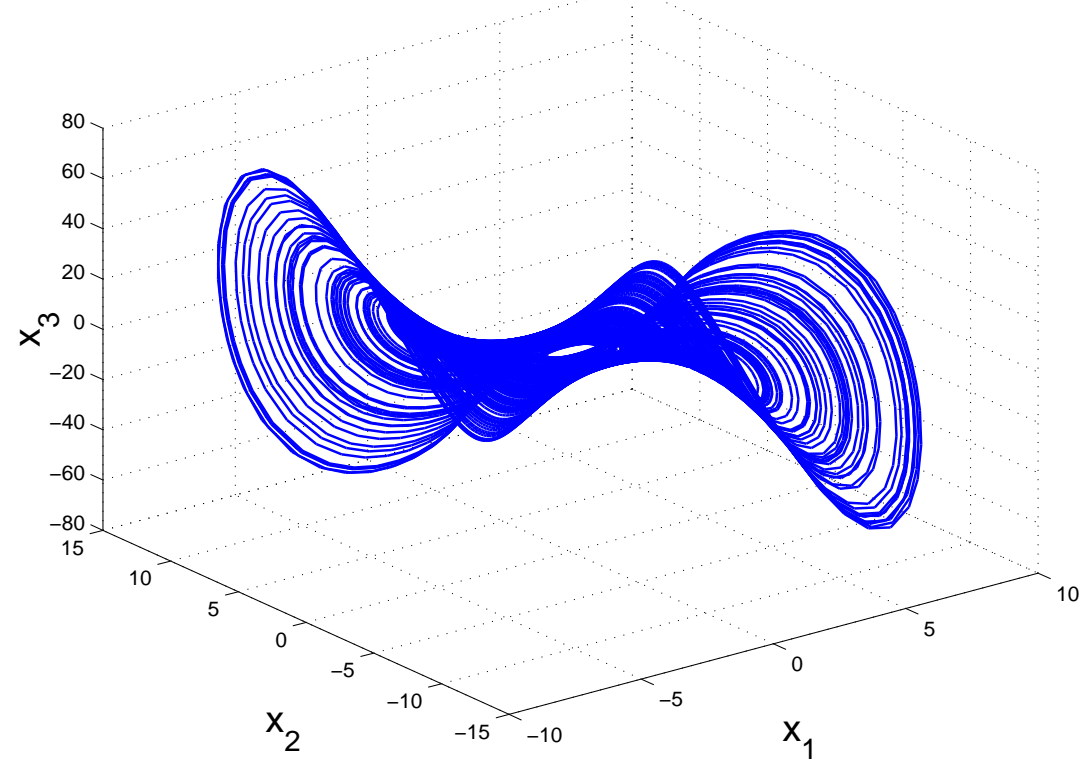

Figure 1: Strange attractor of the 3-D novel jerk chaotic System

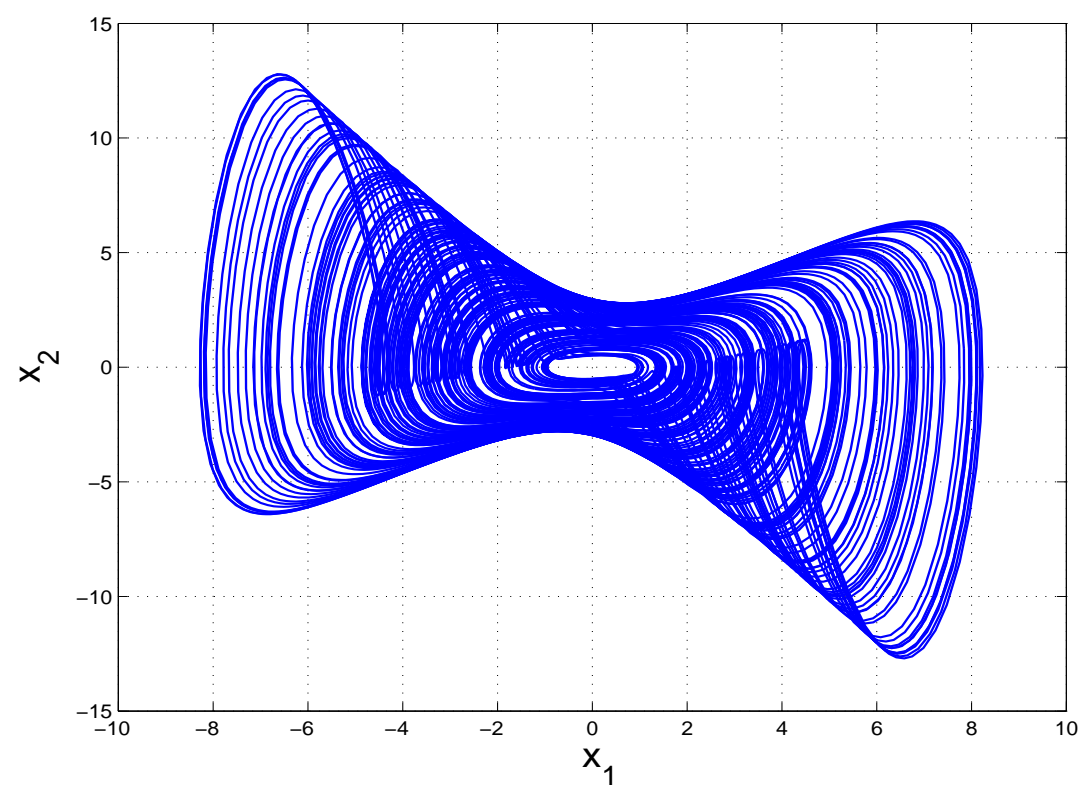

Figure 2: 2-D projection of the novel jerk chaotic system on the $\left(x_{1}, x_{2}\right)$ plane 


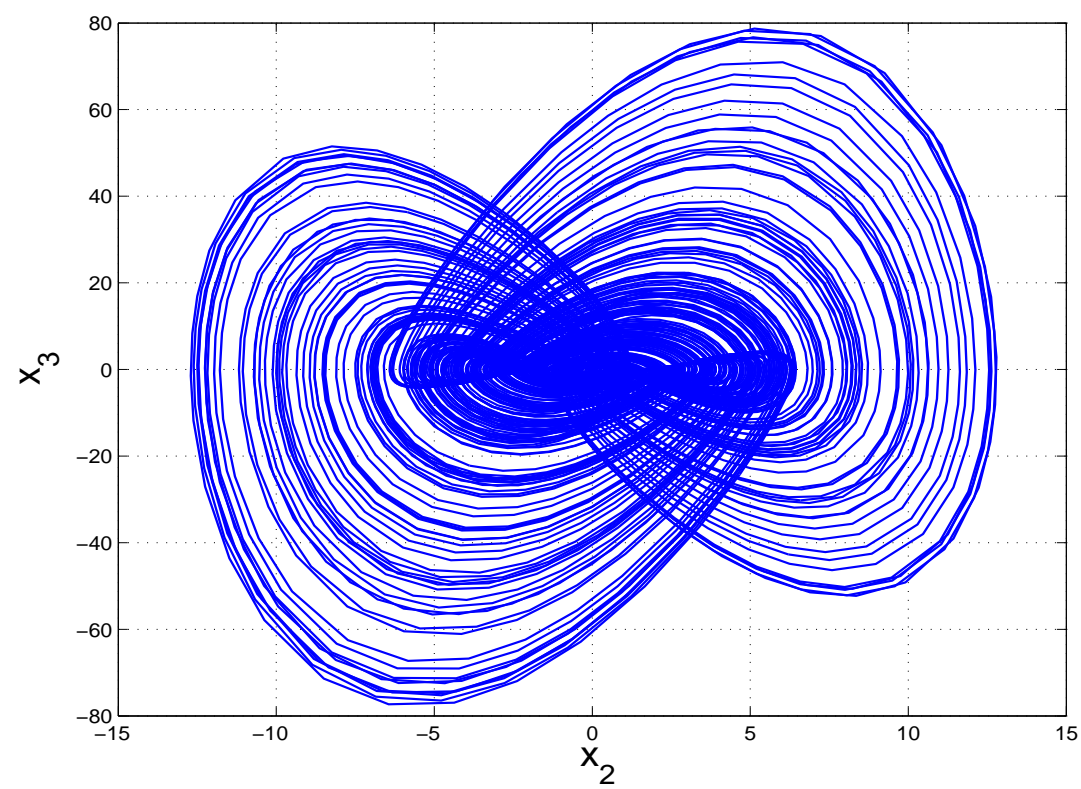

Figure 3: 2-D projection of the novel jerk chaotic system on the $\left(x_{2}, x_{3}\right)$ plane

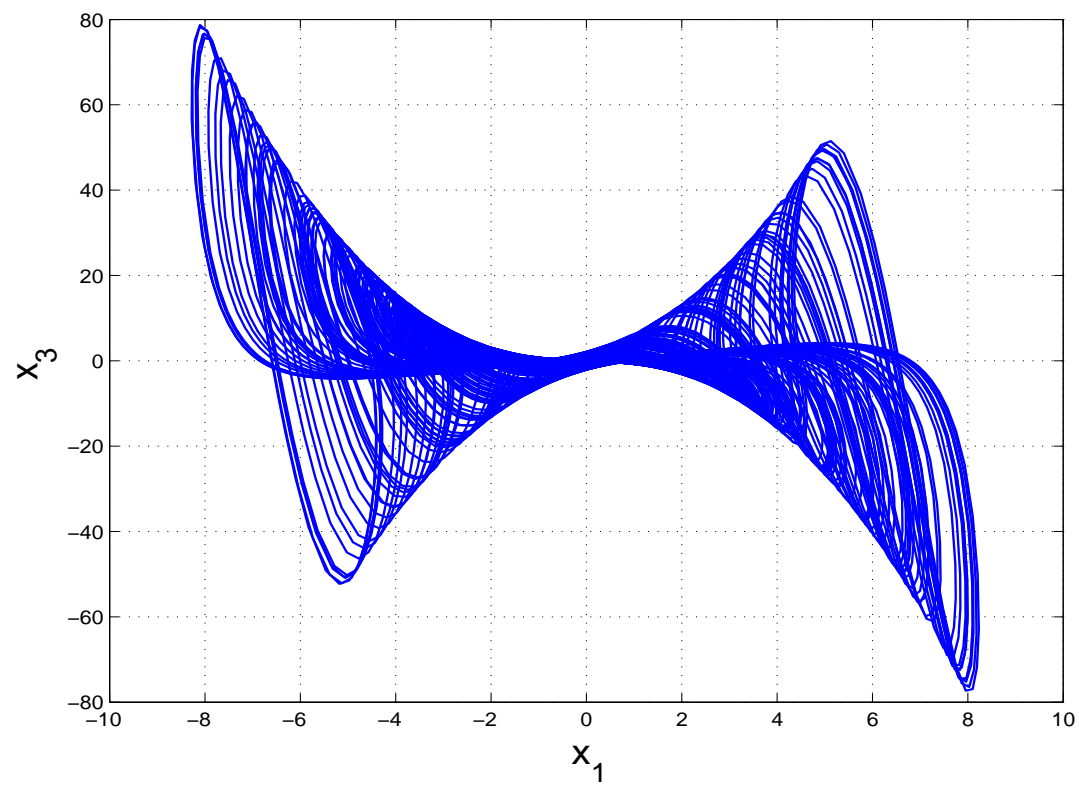

Figure 4: 2-D projection of the novel jerk chaotic system on the $\left(x_{1}, x_{3}\right)$ plane 


\section{Analysis of the 3-D novel jerk chaotic system}

\subsection{Dissipativity}

In vector notation, the new jerk system (9) can be expressed as

$$
\dot{\mathbf{x}}=f(\mathbf{x})=\left[\begin{array}{l}
f_{1}\left(x_{1}, x_{2}, x_{3}\right) \\
f_{2}\left(x_{1}, x_{2}, x_{3}\right) \\
f_{3}\left(x_{1}, x_{2}, x_{3}\right)
\end{array}\right]
$$

where

$$
\left\{\begin{array}{l}
f_{1}\left(x_{1}, x_{2}, x_{3}\right)=x_{2} \\
f_{2}\left(x_{1}, x_{2}, x_{3}\right)=x_{3} \\
f_{3}\left(x_{1}, x_{2}, x_{3}\right)=-a x_{3}-b x_{1}+c x_{2}+x_{1} x_{2}^{2}-x_{1}^{3}
\end{array}\right.
$$

Let $\Omega$ be any region in $\mathbf{R}^{3}$ with a smooth boundary and also, $\Omega(t)=\Phi_{t}(\Omega)$, where $\Phi_{t}$ is the flow of $f$. Furthermore, let $V(t)$ denote the volume of $\Omega(t)$. By Liouville's theorem, we know that

$$
\dot{V}(t)=\int_{\Omega(t)}(\nabla \cdot f) d x_{1} d x_{2} d x_{3}
$$

The divergence of the novel jerk system (14) is found as:

$$
\nabla \cdot f=\frac{\partial f_{1}}{\partial x_{1}}+\frac{\partial f_{2}}{\partial x_{2}}+\frac{\partial f_{3}}{\partial x_{3}}=-a<0
$$

Inserting the value of $\nabla \cdot f$ from (17) into (16), we get

$$
\dot{V}(t)=\int_{\Omega(t)}(-a) d x_{1} d x_{2} d x_{3}=-a V(t)
$$

Integrating the first order linear differential equation (18), we get

$$
V(t)=\exp (-a t) V(0)
$$

From Eq. (19), it is clear that $V(t) \rightarrow 0$ exponentially as $t \rightarrow \infty$. This shows that the novel 3-D jerk chaotic system (9) is dissipative. Hence, the system limit sets are ultimately confined into a specific limit set of zero volume, and the asymptotic motion of the novel jerk chaotic system (9) settles onto a strange attractor of the system.

\subsection{Equilibrium Points}

The equilibrium points of the 3-D novel jerk chaotic system (9) are obtained by solving the equations

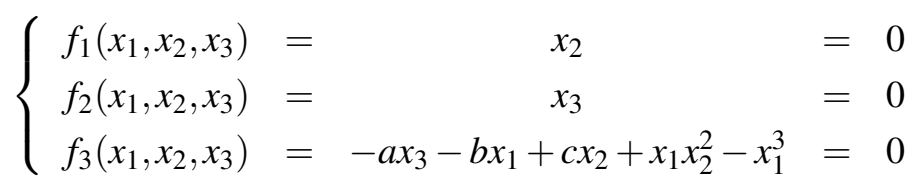


We take the parameter values as in the chaotic case (10), i.e.

$$
a=3.6, b=1.3, c=0.1
$$

Thus, the equilibrium points of the system (9) are characterized by the equations

$$
x_{2}=0, x_{3}=0, x_{1}\left(x_{1}^{2}+b\right)=0
$$

Solving the system (22), we get the equilibrium points of the system (9) as

$$
E_{0}=\left[\begin{array}{l}
0 \\
0 \\
0
\end{array}\right]
$$

The Jacobian matrix of the novel jerk chaotic system (9) at $E_{0}$ is obtained as

$$
J_{0}=J\left(E_{0}\right)=\left[\begin{array}{ccc}
0 & 1 & 0 \\
0 & 0 & 1 \\
-b & c & -a
\end{array}\right]=\left[\begin{array}{ccc}
0 & 1 & 0 \\
0 & 0 & 1 \\
-1.3 & 0.1 & -3.6
\end{array}\right]
$$

We find that $J_{0}$ has the eigenvalues

$$
\lambda_{1}=-3.7208, \quad \lambda_{2,3}=0.0604 \pm 0.5880 i
$$

This shows that the equilibrium $E_{0}$ is a saddle-focus point, which is unstable.

\subsection{Lyapunov exponents and Kaplan-Yorke dimension}

We take the parameter values of the novel jerk system (9) as

$$
a=3.6, b=1.3, c=0.1
$$

Then the Lyapunov exponents are numerically obtained using Wolf's algorithm [146] as

$$
L_{1}=0.2974, L_{2}=0, L_{3}=-3.8974
$$

Thus, the maximal Lyapunov exponent (MLE) of the novel jerk system (9) is $L_{1}=$ $0.2974>0$, which shows that the system (9) has chaotic behavior.

Since $L_{1}+L_{2}+L_{3}=-3.6=-a<0$, it follows that the novel jerk chaotic system (9) is dissipative. Also, the Kaplan-Yorke dimension of the novel jerk chaotic system (9) is obtained as

$$
D_{K Y}=2+\frac{L_{1}+L_{2}}{\left|L_{3}\right|}=2.0763
$$

which is fractional. 


\section{Adaptive control of the 3-D novel jerk chaotic system}

In this section, we use backstepping control method to derive an adaptive feedback control law for globally stabilizing the 3-D novel jerk chaotic system with unknown parameters. Thus, we consider the 3 -D novel jerk chaotic system given by

$$
\left\{\begin{array}{l}
\dot{x}_{1}=x_{2} \\
\dot{x}_{2}=x_{3} \\
\dot{x}_{3}=-a x_{3}-b x_{1}+c x_{2}+x_{1} x_{2}^{2}-x_{1}^{3}+u
\end{array}\right.
$$

where $a, b, c$ are unknown constant parameters, and $u$ is a backstepping control law to be determined using estimates of the unknown system parameters.

The parameter estimation errors are defined as:

$$
\left\{\begin{array}{l}
e_{a}(t)=a-\hat{a}(t) \\
e_{b}(t)=b-\hat{b}(t) \\
e_{c}(t)=c-\hat{c}(t)
\end{array}\right.
$$

Differentiating (30) with respect to $t$, we obtain the following equations:

$$
\left\{\begin{array}{l}
\dot{e}_{a}(t)=-\dot{\hat{a}}(t) \\
\dot{e}_{b}(t)=-\dot{\hat{b}}(t) \\
\dot{e}_{c}(t)=-\dot{\hat{c}}(t)
\end{array}\right.
$$

Next, we shall state and prove the main result of this section.

Theorem 1 The 3-D novel jerk chaotic system (29), with unknown parameters $a, b$ and $c$, is globally and exponentially stabilized by the adaptive feedback control law,

$$
u(t)=-[3-\hat{b}(t)] x_{1}-[5+\hat{c}(t)] x_{2}-[3-\hat{a}(t)] x_{3}-x_{1} x_{2}^{2}+x_{1}^{3}-k z_{3}
$$

where $k>0$ is a gain constant,

$$
z_{3}=2 x_{1}+2 x_{2}+x_{3}
$$

and the update law for the parameter estimates $\hat{a}(t), \hat{b}(t), \hat{c}(t)$ is given by

$$
\left\{\begin{array}{l}
\dot{\hat{a}}(t)=-z_{3} x_{3} \\
\dot{\hat{b}}(t)=-z_{3} x_{1} \\
\dot{\hat{c}}(t)=z_{3} x_{2}
\end{array}\right.
$$


Proof We prove this result via Lyapunov stability theory [145].

First, we define a quadratic Lyapunov function

$$
V_{1}\left(z_{1}\right)=\frac{1}{2} z_{1}^{2}
$$

where

$$
z_{1}=x_{1}
$$

Differentiating $V_{1}$ along the dynamics (29), we get

$$
\dot{V}_{1}=z_{1} \dot{z}_{1}=x_{1} x_{2}=-z_{1}^{2}+z_{1}\left(x_{1}+x_{2}\right)
$$

Now, we define

$$
z_{2}=x_{1}+x_{2}
$$

Using (38), we can simplify the equation (37) as

$$
\dot{V}_{1}=-z_{1}^{2}+z_{1} z_{2}
$$

Secondly, we define a quadratic Lyapunov function

$$
V_{2}\left(z_{1}, z_{2}\right)=V_{1}\left(z_{1}\right)+\frac{1}{2} z_{2}^{2}=\frac{1}{2}\left(z_{1}^{2}+z_{2}^{2}\right)
$$

Differentiating $V_{2}$ along the dynamics (29), we get

$$
\dot{V}_{2}=-z_{1}^{2}-z_{2}^{2}+z_{2}\left(2 x_{1}+2 x_{2}+x_{3}\right)
$$

Now, we define

$$
z_{3}=2 x_{1}+2 x_{2}+x_{3}
$$

Using (42), we can simplify the equation (41) as

$$
\dot{V}_{2}=-z_{1}^{2}-z_{2}^{2}+z_{2} z_{3}
$$

Finally, we define a quadratic Lyapunov function

$$
V\left(z_{1}, z_{2}, z_{3}, e_{a}, e_{b}, e_{c}\right)=V_{2}\left(z_{1}, z_{2}\right)+\frac{1}{2} z_{3}^{2}+\frac{1}{2}\left(e_{a}^{2}+e_{b}^{2}+e_{c}^{2}\right)
$$

which is a positive definite function on $\mathbf{R}^{6}$. Differentiating $V$ along the dynamics (29), we get

$$
\dot{V}=-z_{1}^{2}-z_{2}^{2}-z_{3}^{2}+z_{3}\left(z_{3}+z_{2}+\dot{z}_{3}\right)-e_{a} \dot{\hat{a}}-e_{b} \dot{\hat{b}}-e_{c} \dot{\hat{c}}
$$

Eq. (45) can be written compactly as

$$
\dot{V}=-z_{1}^{2}-z_{2}^{2}-z_{3}^{2}+z_{3} S-e_{a} \dot{\hat{a}}-e_{b} \dot{\hat{b}}-e_{c} \dot{\hat{c}}
$$


where

$$
S=z_{3}+z_{2}+\dot{z}_{3}=z_{3}+z_{2}+2 \dot{x}_{1}+2 \dot{x}_{2}+\dot{x}_{3}
$$

A simple calculation gives

$$
S=(3-b) x_{1}+(5+c) x_{2}+(3-a) x_{3}+x_{1} x_{2}^{2}-x_{1}^{3}+u
$$

Substituting the adaptive control law (32) into (48), we obtain

$$
S=-[b-\hat{b}(t)] x_{1}+[c-\hat{c}(t)] x_{2}-[a-\hat{a}(t)] x_{3}-k z_{3}
$$

Using the definitions (31), we can simplify (49) as

$$
S=-e_{b} x_{1}+e_{c} x_{2}-e_{a} x_{3}-k z_{3}
$$

Substituting the value of $S$ from (50) into (46), we obtain

$$
\dot{V}=-z_{1}^{2}-z_{2}^{2}-(1+k) z_{3}^{2}+e_{a}\left(-z_{3} x_{3}-\dot{\hat{a}}\right)+e_{b}\left(-z_{3} x_{1}-\dot{\hat{b}}\right)+e_{c}\left(z_{3} x_{2}-\dot{\hat{c}}\right)
$$

Substituting the update law (34) into (51), we get

$$
\dot{V}=-z_{1}^{2}-z_{2}^{2}-(1+k) z_{3}^{2},
$$

which is a negative semi-definite function on $\mathbf{R}^{6}$. From (52), it follows that the vector $\mathbf{z}(t)=\left(z_{1}(t), z_{2}(t), z_{3}(t)\right)$ and the parameter estimation error $\left.\left(e_{a}(t), e_{b}(t), e_{c}(t)\right)\right)$ are globally bounded, i.e.

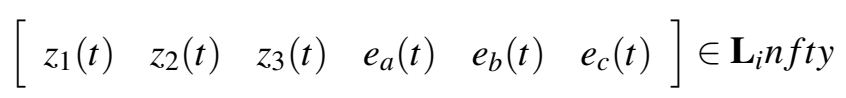

Also, it follows from (52) that

$$
\dot{V} \leqslant-z_{1}^{2}-z_{2}^{2}-z_{3}^{2}=-\|\mathbf{z}\|^{2}
$$

That is,

$$
\|\mathbf{z}\|^{2} \leqslant-\dot{V}
$$

Integrating the inequality (55) from 0 to $t$, we get

$$
\int_{0}^{t}|\mathbf{z}(\tau)|^{2} d \tau \leqslant V(0)-V(t)
$$

From (56), it follows that $\mathbf{z}(t) \in \mathbf{L}_{2}$. From Eq. (29), it can be deduced that $\dot{\mathbf{z}}(t) \in \mathbf{L}_{\infty}$. Thus, using Barbalat's lemma [145], we conclude that $\mathbf{z}(t) \rightarrow \mathbf{0}$ exponentially as $t \rightarrow \infty$ for all initial conditions $\mathbf{z}(0) \in \mathbf{R}^{3}$. Hence, it is immediate that $\mathbf{x}(t) \rightarrow \mathbf{0}$ exponentially as $t \rightarrow \infty$ for all initial conditions $\mathbf{x}(0) \in \mathbf{R}^{3}$. This completes the proof. 
For the numerical simulations, the classical fourth-order Runge-Kutta method with step size $h=10^{-8}$ is used to solve the system of differential equations (29) and (34), when the adaptive control law (32) is applied.

The parameter values of the novel jerk chaotic system (29) are taken as in the chaotic case (10), i.e.

$$
a=3.6, b=1.3, c=0.1
$$

The positive gain constant $k$ is taken as $k=10$. As initial conditions of the novel jerk chaotic system (29), we take

$$
x_{1}(0)=7.5, \quad x_{2}(0)=12.1, \quad x_{3}(0)=15.4
$$

Also, as initial conditions of the parameter estimates, we take

$$
\hat{a}(0)=3.1, \hat{b}(0)=6.8, \quad \hat{c}(0)=9.2
$$

In Figure 5, the exponential convergence of the controlled states is depicted, when the adaptive control law (32) and parameter update law (34) are implemented.

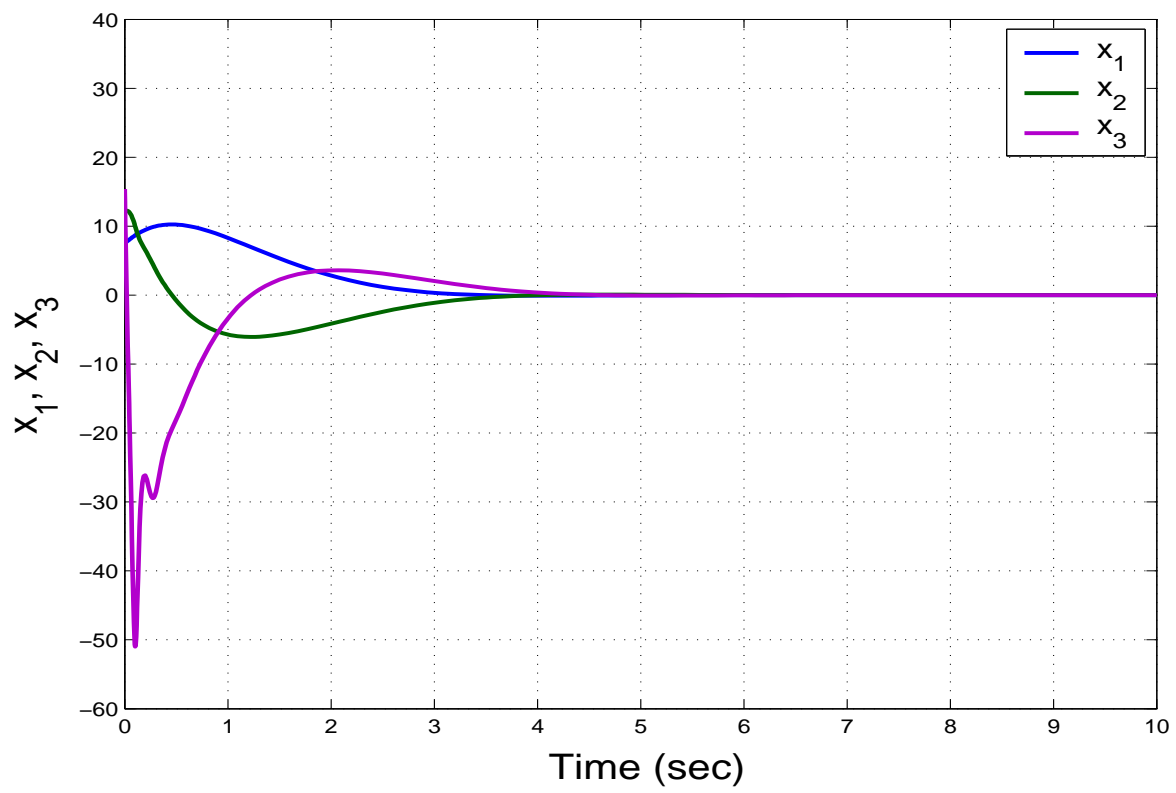

Figure 5: Time-history of the controlled states $x_{1}(t), x_{2}(t), x_{3}(t)$

\section{Adaptive synchronization of the identical 3-D novel jerk chaotic systems}

In this section, we use backstepping control method to derive an adaptive control law for globally and exponentially synchronizing the identical 3-D novel jerk chaotic systems with unknown parameters. 
As the master system, we consider the 3-D novel jerk chaotic system given by

$$
\left\{\begin{array}{l}
\dot{x}_{1}=x_{2} \\
\dot{x}_{2}=x_{3} \\
\dot{x}_{3}=-a x_{3}-b x_{1}+c x_{2}+x_{1} x_{2}^{2}-x_{1}^{3}
\end{array}\right.
$$

where $x_{1}, x_{2}, x_{3}$ are the states of the system, and $a, b, c$ are unknown constant parameters.

As the slave system, we consider the 3-D novel jerk chaotic system given by

$$
\left\{\begin{array}{l}
\dot{y}_{1}=y_{2} \\
\dot{y}_{2}=y_{3} \\
\dot{y}_{3}=-a y_{3}-b y_{1}+c y_{2}+y_{1} y_{2}^{2}-y_{1}^{3}+u
\end{array}\right.
$$

where $y_{1}, y_{2}, y_{3}$ are the states of the system, and $u$ is a backstepping control to be determined using estimates of the unknown system parameters.

We define the synchronization errors between the states of the master system (60) and the slave system (61) as

$$
\left\{\begin{array}{l}
e_{1}=y_{1}-x_{1} \\
e_{2}=y_{2}-x_{2} \\
e_{3}=y_{3}-x_{3}
\end{array}\right.
$$

Then the error dynamics is easily obtained as

$$
\left\{\begin{array}{l}
\dot{e}_{1}=e_{2} \\
\dot{e}_{2}=e_{3} \\
\dot{e}_{3}=-a e_{3}-b e_{1}+c e_{2}+y_{1} y_{2}^{2}-x_{1} x_{2}^{2}-y_{1}^{3}+x_{1}^{3}+u
\end{array}\right.
$$

The parameter estimation errors are defined as:

$$
\left\{\begin{array}{l}
e_{a}(t)=a-\hat{a}(t) \\
e_{b}(t)=b-\hat{b}(t) \\
e_{c}(t)=c-\hat{c}(t)
\end{array}\right.
$$

Differentiating (64) with respect to $t$, we obtain the following equations:

$$
\left\{\begin{array}{l}
\dot{e}_{a}(t)=-\dot{\hat{a}}(t) \\
\dot{e}_{b}(t)=-\dot{\hat{b}}(t) \\
\dot{e}_{c}(t)=-\dot{\hat{c}}(t)
\end{array}\right.
$$

Next, we shall state and prove the main result of this section. 
Theorem 2 The identical 3-D novel jerk chaotic systems (60) and (61) with unknown parameters $a, b$ and $c$ are globally and exponentially synchronized by the adaptive control law

$$
\left\{\begin{aligned}
u(t)= & -[3-\hat{b}(t)] e_{1}-[5+\hat{c}(t)] e_{2}-[3-\hat{a}(t)] e_{3} \\
& -y_{1} y_{2}^{2}+x_{1} x_{2}^{2}+y_{1}^{3}-x_{1}^{3}-k z_{3}
\end{aligned}\right.
$$

where $k>0$ is a gain constant,

$$
z_{3}=2 e_{1}+2 e_{2}+e_{3}
$$

and the update law for the parameter estimates $\hat{a}(t), \hat{b}(t)$ is given by

$$
\left\{\begin{array}{l}
\dot{\hat{a}}(t)=-z_{3} e_{3} \\
\dot{\hat{b}}(t)=-z_{3} e_{1} \\
\dot{\hat{c}}(t)=z_{3} e_{2}
\end{array}\right.
$$

Proof We prove this result via backstepping control method and Lyapunov stability theory.

First, we define a quadratic Lyapunov function

$$
V_{1}\left(z_{1}\right)=\frac{1}{2} z_{1}^{2}
$$

where

$$
z_{1}=e_{1}
$$

Differentiating $V_{1}$ along the error dynamics (63), we get

$$
\dot{V}_{1}=z_{1} \dot{z}_{1}=e_{1} e_{2}=-z_{1}^{2}+z_{1}\left(e_{1}+e_{2}\right)
$$

Now, we define

$$
z_{2}=e_{1}+e_{2}
$$

Using (72), we can simplify the equation (71) as

$$
\dot{V}_{1}=-z_{1}^{2}+z_{1} z_{2}
$$

Secondly, we define a quadratic Lyapunov function

$$
V_{2}\left(z_{1}, z_{2}\right)=V_{1}\left(z_{1}\right)+\frac{1}{2} z_{2}^{2}=\frac{1}{2}\left(z_{1}^{2}+z_{2}^{2}\right)
$$

Differentiating $V_{2}$ along the error dynamics (63), we get

$$
\dot{V}_{2}=-z_{1}^{2}-z_{2}^{2}+z_{2}\left(2 e_{1}+2 e_{2}+e_{3}\right)
$$


Now, we define

$$
z_{3}=2 e_{1}+2 e_{2}+e_{3}
$$

Using (76), we can simplify the equation (75) as

$$
\dot{V}_{2}=-z_{1}^{2}-z_{2}^{2}+z_{2} z_{3}
$$

Finally, we define a quadratic Lyapunov function

$$
V\left(z_{1}, z_{2}, z_{3}, e_{a}, e_{b}, e_{c}, e_{p}\right)=V_{2}\left(z_{1}, z_{2}\right)+\frac{1}{2} z_{3}^{2}+\frac{1}{2}\left(e_{a}^{2}+e_{b}^{2}+e_{c}^{2}\right)
$$

which is a positive definite function on $\mathbf{R}^{6}$. Differentiating $V$ along the error dynamics (63), we get

$$
\dot{V}=-z_{1}^{2}-z_{2}^{2}-z_{3}^{2}+z_{3}\left(z_{3}+z_{2}+\dot{z}_{3}\right)-e_{a} \dot{\hat{a}}-e_{b} \dot{\hat{b}}-e_{c} \dot{\hat{c}}
$$

Eq. (79) can be written compactly as

$$
\dot{V}=-z_{1}^{2}-z_{2}^{2}-z_{3}^{2}+z_{3} S-e_{a} \dot{\hat{a}}-e_{b} \dot{\hat{b}}-e_{c} \dot{\hat{c}}
$$

where

$$
S=z_{3}+z_{2}+\dot{z}_{3}=z_{3}+z_{2}+2 \dot{e}_{1}+2 \dot{e}_{2}+\dot{e}_{3}
$$

A simple calculation gives

$$
S=(3-b) e_{1}+(5+c) e_{2}+(3-a) e_{3}+y_{1} y_{2}^{2}-x_{1} x_{2}^{2}-y_{1}^{3}+x_{1}^{3}+u
$$

Substituting the adaptive control law (66) into (48), we obtain

$$
S=-[b-\hat{b}(t)] e_{1}+[c-\hat{c}(t)] e_{2}-[a-\hat{a}(t)] e_{3}-k z_{3}
$$

Using the definitions (65), we can simplify (83) as

$$
S=-e_{b} e_{1}+e_{c} e_{2}-e_{a} e_{3}-k z_{3}
$$

Substituting the value of $S$ from (84) into (80), we obtain

$$
\left\{\begin{aligned}
\dot{V}= & -z_{1}-z_{2}-(1+k) z_{3}^{2}+e_{a}\left[-z_{3} e_{3}-\dot{\hat{a}}\right]+e_{b}\left[-z_{3} e_{1}-\dot{\hat{b}}\right] \\
& +e_{c}\left[z_{3} e_{2}-\dot{\hat{c}}\right]
\end{aligned}\right.
$$

Substituting the update law (68) into (85), we get

$$
\dot{V}=-z_{1}^{2}-z_{2}^{2}-(1+k) z_{3}^{2}
$$

which is a negative semi-definite function on $\mathbf{R}^{6}$. From (86), it follows that the vector $\mathbf{z}(t)=\left(z_{1}(t), z_{2}(t), z_{3}(t)\right)$ and the parameter estimation error $\left(e_{a}(t), e_{b}(t), e_{c}(t)\right)$ are globally bounded, i.e.

$$
\left[\begin{array}{llllll}
z_{1}(t) & z_{2}(t) & z_{3}(t) & e_{a}(t) & e_{b}(t) & e_{c}(t)
\end{array}\right] \in \mathbf{L}_{i} n f t y
$$


Also, it follows from (86) that

$$
\dot{V} \leqslant-z_{1}^{2}-z_{2}^{2}-z_{3}^{2}=-\|\mathbf{z}\|^{2}
$$

That is,

$$
\|\mathbf{z}\|^{2} \leqslant-\dot{V}
$$

Integrating the inequality (89) from 0 to $t$, we get

$$
\int_{0}^{t}|\mathbf{z}(\tau)|^{2} d \tau \leqslant V(0)-V(t)
$$

From (90), it follows that $\mathbf{z}(t) \in \mathbf{L}_{2}$. From Eq. (63), it can be deduced that $\dot{\mathbf{z}}(t) \in \mathbf{L}_{\infty}$. Thus, using Barbalat's lemma, we conclude that $\mathbf{z}(t) \rightarrow \mathbf{0}$ exponentially as $t \rightarrow \infty$ for all initial conditions $\mathbf{z}(0) \in \mathbf{R}^{3}$. Hence, it is immediate that $\mathbf{e}(t) \rightarrow \mathbf{0}$ exponentially as $t \rightarrow \infty$ for all initial conditions $\mathbf{e}(0) \in \mathbf{R}^{3}$. This completes the proof.

For the numerical simulations, the classical fourth-order Runge-Kutta method with step size $h=10^{-8}$ is used to solve the system of differential equations (60) and (61).

The parameter values of the novel jerk chaotic systems are taken as in the chaotic case, (10), i.e.

$$
a=3.6, b=1.3, c=0.1
$$

The positive gain constant is taken as $k=10$. As initial conditions of the master chaotic system (60), we take

$$
x_{1}(0)=-5.8, \quad x_{2}(0)=3.7, \quad x_{3}(0)=-4.9
$$

As initial conditions of the slave chaotic system (61), we take

$$
y_{1}(0)=4.5, \quad y_{2}(0)=8.4, \quad y_{3}(0)=-8.5
$$

Also, as initial conditions of the parameter estimates, we take

$$
\hat{a}(0)=11.2, \quad \hat{b}(0)=6.1, \quad \hat{c}(0)=12.6
$$

In Figs. 6-8, the complete synchronization of the identical 3-D jerk chaotic systems (60) and (61) is shown, when the adaptive control law (66) and the parameter update law (68) are implemented.

Also, in Fig. 9, the time-history of the synchronization errors $e_{1}(t), e_{2}(t), e_{3}(t)$, is shown. 


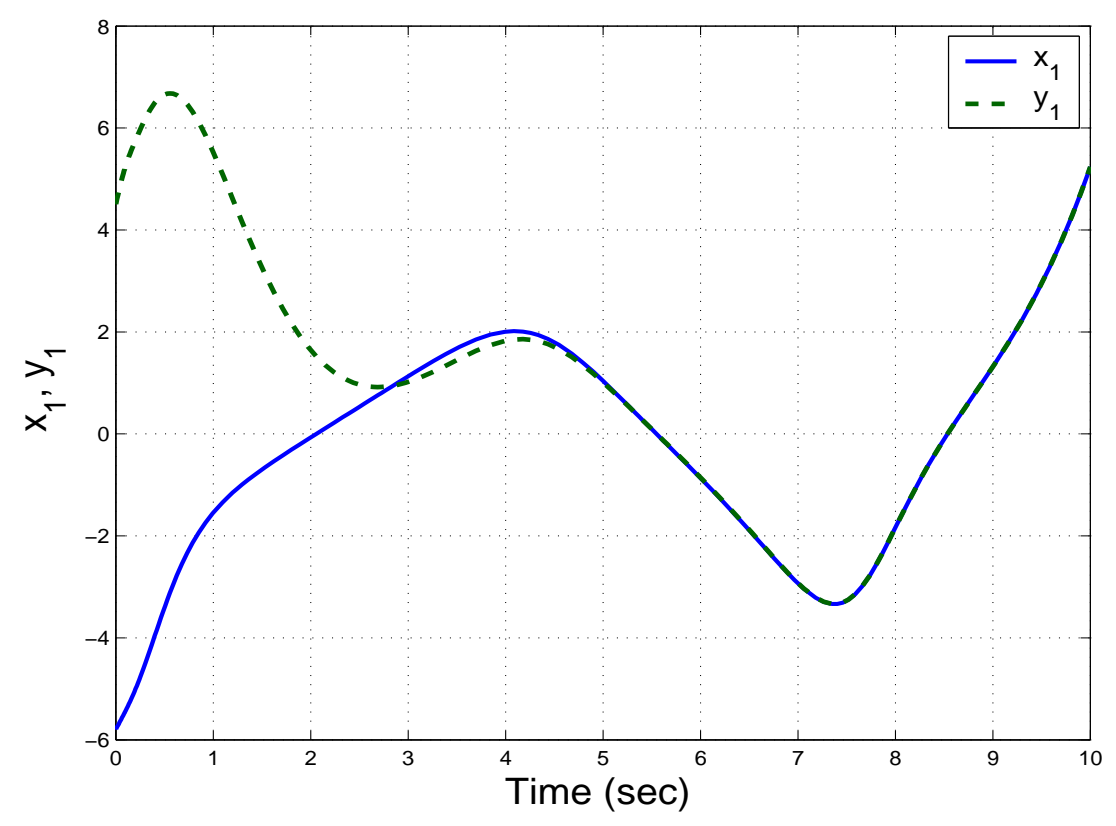

Figure 6: Synchronization of the states $x_{1}(t)$ and $y_{1}(t)$

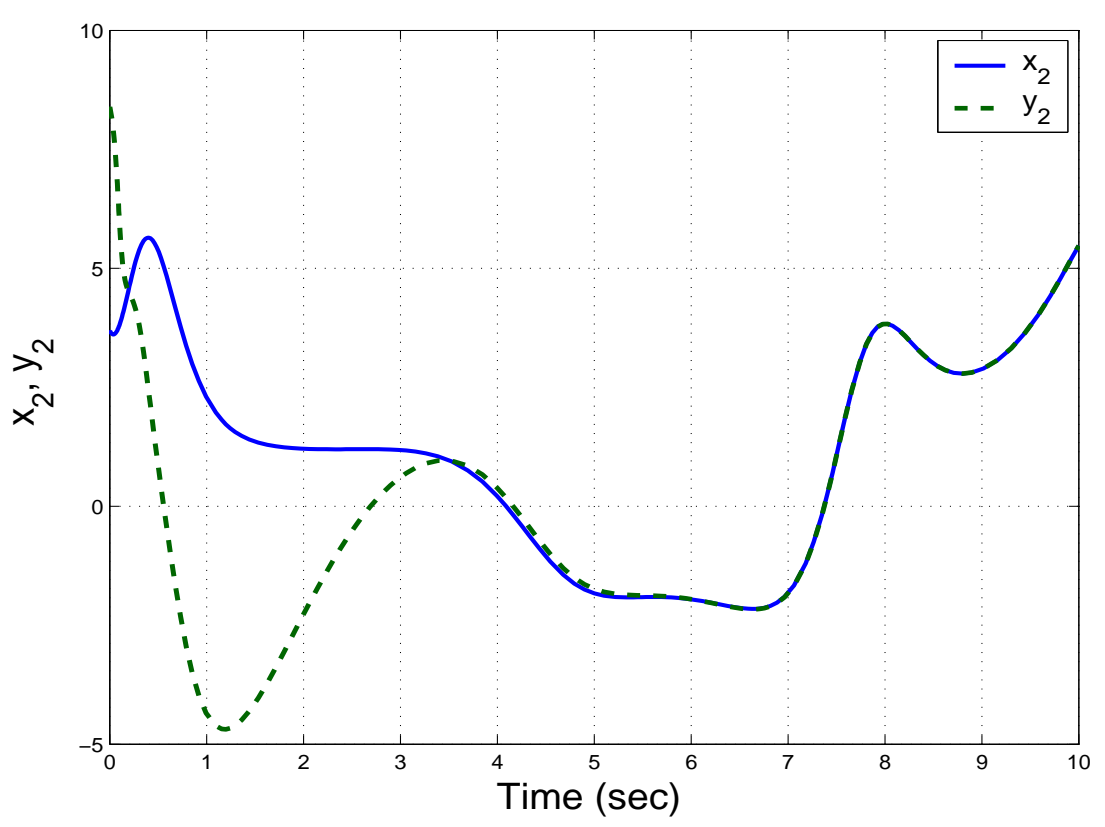

Figure 7: Synchronization of the states $x_{2}(t)$ and $y_{2}(t)$ 


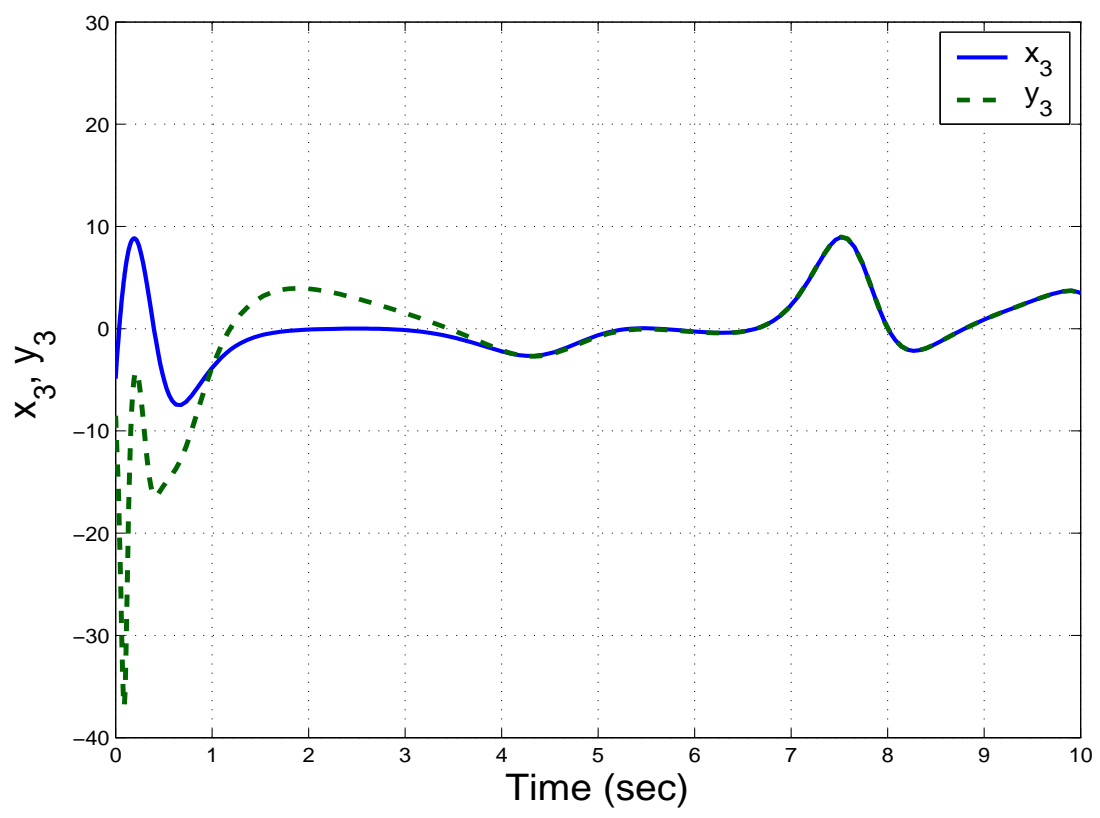

Figure 8: Synchronization of the states $x_{3}(t)$ and $y_{3}(t)$

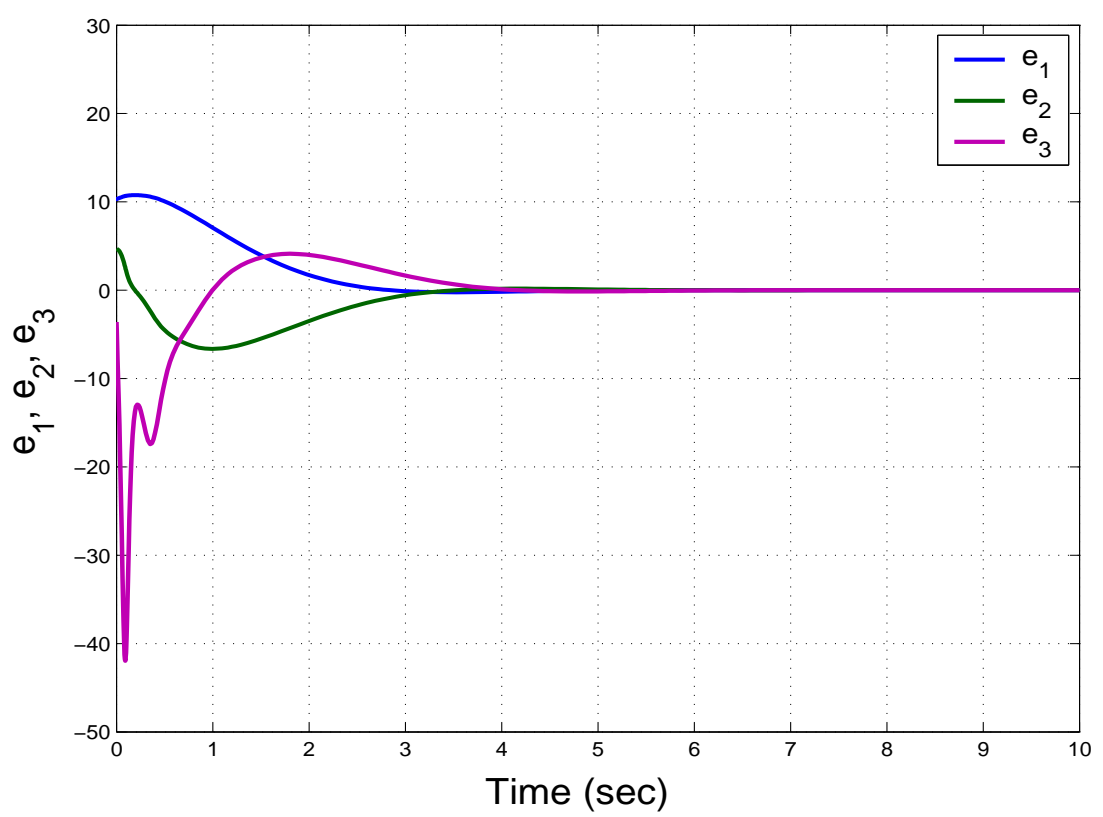

Figure 9: Time-history of the synchronization errors $e_{1}(t), e_{2}(t), e_{3}(t)$ 


\section{Conclusions}

In this paper, we announced a seven-term novel 3-D jerk chaotic system with two cubic nonlinearities. The phase portraits of the novel jerk chaotic system were displayed and the qualitative properties were discussed. Next, an adaptive backstepping controller was designed to globally stabilize the novel jerk chaotic system with unknown parameters. Moreover, an adaptive backstepping controller was also designed to achieve global chaos synchronization of the identical jerk chaotic systems with unknown parameters. MATLAB simulations were depicted to illustrate the phase portraits of the novel jerk chaotic system and also the adaptive backstepping control results.

\section{References}

[1] A.T. AZAR and S. VAIDYANATHAN: Chaos Modeling and Control Systems Design. Springer, Berlin, Germany, 2015.

[2] S. VAIDYANATHAN and C. VOLOS: Advances and Applications in Chaotic Systems. Springer, Berlin, Germany, 2016.

[3] A.T. AZAR and S. VAIDYANATHAN: Advances in Chaos Theory and Intelligent Control. Springer, Berlin, Germany, 2016.

[4] E.N. LORENZ: Deterministic nonperiodic flow. Journal of the Atmospheric Sciences, 20 (1963), 130-141.

[5] G. CHEN and T. UETA: Yet another chaotic attractor. International Journal of Bifurcation and Chaos, 9 (1999), 1465-1466.

[6] J. LÜ and G. CHEN: A new chaotic attractor coined. International Journal of Bifurcation and Chaos, 12 (2002), 659-661.

[7] G. CAI and Z. TAN: Chaos synchronization of a new chaotic system via nonlinear control. Journal of Uncertain Systems, 1 (2007), 235-240.

[8] G. TIGAN and D. OPRIS: Analysis of a 3D chaotic system. Chaos, Solitons and Fractals, 36 (2008), 1315-1319.

[9] J.C. SPROTT: Some simple chaotic flows. Physical Review E, 50 (1994), 647-650.

[10] A. ARNEODO, P. COULLET and C. TRESSER: Possible new strange attractors with spiral structure. Communications in Mathematical Physics, 79 (1981), 573579 .

[11] J.C. SPROTT: Some simple chaotic flows. Physical Review E, 50 (1994), 647-650. 
[12] M. HÉNON and C. HEILES: The applicability of the third integral of motion: Some numerical experiments. Astrophysical Journal, 69 (1964), 73-79.

[13] J. LÜ and G. CHEN: A new chaotic attractor coined. International Journal of Bifurcation and Chaos, 12 (2002), 659-661.

[14] C.X. LIU, T. LIU, L. LIU and K. LIU: A new chaotic attractor. Chaos, Solitons and Fractals, 22 (2004), 1031-1038.

[15] D. LI: A three-scroll chaotic attractor. Physics Letters A, 372 (2008), 387-393.

[16] V. SUNDARAPANDIAN and I. PEHLIVAN: Analysis, control, synchronization and circuit design of a novel chaotic system. Mathematical and Computer Modelling, 55 (2012), 1904-1915.

[17] V. SUNDARAPANDIAN: Analysis and anti-synchronization of a novel chaotic system via active and adaptive controllers. Journal of Engineering Science and Technology Review, 6 (2013), 45-52.

[18] S. VAIDYANATHAN: A new six-term 3-D chaotic system with an exponential nonlinearity. Far East Journal of Mathematical Sciences, 79 (2013), 135-143.

[19] S. VAIDYANATHAN: Analysis and adaptive synchronization of two novel chaotic systems with hyperbolic sinusoidal and cosinusoidal nonlinearity and unknown parameters. Journal of Engineering Science and Technology Review, 6 (2013), 53-65.

[20] S. VAIDYANATHAN: A new eight-term 3-D polynomial chaotic system with three quadratic nonlinearities. Far East Journal of Mathematical Sciences, 84 (2014), 219-226.

[21] S. VAIDYANATHAN: Analysis, control and synchronisation of a six-term novel chaotic system with three quadratic nonlinearities. International Journal of Modelling, Identification and Control, 22 (2014), 41-53.

[22] S. VAIDYANATHAN and K. MADHAVAN: Analysis, adaptive control and synchronization of a seven-term novel 3-D chaotic system. International Journal of Control Theory and Applications, 6 (2013), 121-137.

[23] S. VAIDYANATHAN: Analysis and adaptive synchronization of eight-term 3-D polynomial chaotic systems with three quadratic nonlinearities. European Physical Journal: Special Topics, 223 (2014), 1519-1529.

[24] S. VAIDYANATHAN, CH. VOLOS, V.T. PHAM, K. MADHAVAN and B.A. IDOWU: Adaptive backstepping control, synchronization and circuit simulation of a 3-D novel jerk chaotic system with two hyperbolic sinusoidal nonlinearities. Archives of Control Sciences, 24 (2014), 257-285. 
[25] S. VAIDYANATHAN: Generalised projective synchronisation of novel 3-D chaotic systems with an exponential non-linearity via active and adaptive control. International Journal of Modelling, Identification and Control, 22 (2014), 207-217.

[26] S. VAIDYANATHAN: Analysis, properties and control of an eight-term 3-D chaotic system with an exponential nonlinearity. International Journal of Modelling, Identification and Control, 23 (2015), 164-172.

[27] S. VAIDYANATHAN: A 3-D novel highly chaotic system with four quadratic nonlinearities, its adaptive control and anti-synchronization with unknown parameters. Journal of Engineering Science and Technology Review, 8 (2015), 106-115.

[28] S. VAIDYANATHAN, K. RAJAGOPAL, C.K. VOLOS, I.M. KYPRIANIDIS and I.N. STOUBOULOS: Analysis, adaptive control and synchronization of a seventerm novel 3-D chaotic system with three quadratic nonlinearities and its digital implementation in LabVIEW. Journal of Engineering Science and Technology Review, 8 (2015), 130-141.

[29] S. VAIDYANATHAN, C.K. VOLOS, I.M. KYPRIANIDIS, I.N. STOUBOULOS and V.-T. PHAM: Analysis, adaptive control and anti-synchronization of a sixterm novel jerk chaotic system with two exponential nonlinearities and its circuit simulation. Journal of Engineering Science and Technology Review, 8 (2015), 2436.

[30] S. VAIDYANATHAN, C.K. VOLOS and V.-T. PHAM: Analysis, adaptive control and adaptive synchronization of a nine-term novel 3-D chaotic system with four quadratic nonlinearities and its circuit simulation. Journal of Engineering Science and Technology Review, 8 (2015), 174-184.

[31] S. VAIDYANATHAN and C. VOLOS: Analysis and adaptive control of a novel 3-D conservative no-equilibrium chaotic system. Archives of Control Sciences, 25 (2015), 333-353.

[32] S. VAIDYANATHAN: Analysis, control, and synchronization of a 3-D novel jerk chaotic system with two quadratic nonlinearities. Kyungpook Mathematical Journal, 55 (2015), 563-586.

[33] S. VAIDYANATHAN and S. PAKIRISWAMY: A 3-D novel conservative chaotic system and its generalized projective synchronization via adaptive control. Journal of Engineering Science and Technology Review, 8 (2015), 52-60.

[34] I. PEHLIVAN, I.M. MOROZ and S. VAIDYANATHAN: Analysis, synchronization and circuit design of a novel butterfly attractor. Journal of Sound and Vibration, 333 (2014), 5077-5096. 
[35] O.I. TACHA, C.K. VOLOS, I.M. KYPRIANIDIS, I.N. STOUBOULOS, S. VAIDYANATHAN and V.-T. PHAM: Analysis, adaptive control and circuit simulation of a novel nonlinear finance system. Applied Mathematics and Computation, 276 (2016), 200-217.

[36] S. JAFARI and J.C. SPROTT: Simple chaotic flows with a line equilibrium. Chaos, Solitons and Fractals, 57 (2013), 79-84.

[37] S. SAMPATH, S. VAIDYANATHAN, C.K. VOLOS and V.T. PHAM: An eightterm novel four-scroll chaotic system with cubic nonlinearity and its circuit simulation. Journal of Engineering Science and Technology Review, 8 (2015), 1-6.

[38] V.T. PHAM, C.K. VOLOS and S. VAIDYANATHAN: Multi-scroll chaotic oscillator based on a first-order delay differential equation. Studies in Computational Intelligence, 581 (2015), 59-72.

[39] V.T. PHAM, C. VOLOS, S. JAFARI, Z. WEI and X. WANG: Constructing a novel no-equilibrium chaotic system. International Journal of Bifurcation and Chaos, 24 (2014), 1450073.

[40] V.T. PHAM, S. VAIDYANATHAN, C.K. VOLOS and S. JAFARI: Hidden attractors in a chaotic system with an exponential nonlinear term. European Physical Journal: Special Topics, 224 (2015), 1507-1517.

[41] V.T. PHAM, S. VAIDYANATHAN, C. VOLOS, S. JAFARI and S.T. KINGNI: A no-equilibrium hyperchaotic system with a cubic nonlinear term. Optik, 127 (6), (2016), 3259-3265.

[42] V.T. PHAM, C. VOLOS and S. VAIDYANATHAN: Chaotic attractor in a novel time-delayed system with a saturation function. Handbook of Research on Advanced Intelligence Control Engineering and Automation, (2015), 230-258.

[43] V.T. PHAM, S. JAFARI, C. VOLOS, A. GIAKOUMIS, S. VAIDYANATHAN and T. KAPITANIAK: A chaotic system with equilibria located on the rounded square loop and its circuit implementation. IEEE Transactions on Circuits and Systems-II: Express Briefs, 63 (9), (2016), 878-882.

[44] V.T. PHAM, S. JAFARI, C. VOLOS, S. VAIDYANATHAN and T. KAPITANIAK: A chaotic system with infinite equilibria located on a piecewise linear curve. Optik, 127 (2016), 9111-9117.

[45] C. VOLOS, J.O. MAAITA, S. VAIDYANATHAN, V.T. PHAM, I. STOUBOULOS and I. KYPRIANIDIS: A novel four-dimensional hyperchaotic four-wing system with a saddle-focus equilibrium. IEEE Transactions on Circuits and Systems-II: Express Briefs, 64 (3), (2017), 339-343. 
[46] A. AKGUL, I. MOROZ, I. PEHLIVAN and S. VAIDYANATHAN: A new fourscroll chaotic attractor and its engineering applications. Optik, 127 (2016), 54915499 .

[47] S. VAIDYANATHAN: Anti-synchronization of Mathieu-Van der Pol chaotic systems via adaptive control method. International Journal of ChemTech Research, $\mathbf{8}$ (11), (2015), 638-653.

[48] S. VAIDYANATHAN: Global chaos synchronization of novel coupled Van der Pol conservative chaotic systems via adaptive control method. International Journal of PharmTech Research, 8 (8), (2015), 95-111.

[49] S. VAIDYANATHAN: Global chaos synchronization of the forced Van der Pol chaotic oscillators via adaptive control method. International Journal of PharmTech Research, 8 (6), (2015), 156-166.

[50] S. VAIDYANATHAN: Sliding controller design for the global chaos synchronization of forced Van der Pol chaotic oscillators. International Journal of PharmTech Research, 8 (7), (2015), 100-111.

[51] S. VAIDYANATHAN: Output regulation of the forced Van der Pol chaotic oscillator via adaptive control method. International Journal of PharmTech Research, $\mathbf{8}$ (6), (2015), 106-116.

[52] S. VAIDYANATHAN: Global chaos synchronization of Mathieu-Van der Pol chaotic systems via adaptive control method. International Journal of ChemTech Research, 8 (10), (2015), 148-162.

[53] S. VAIDYANATHAN: A novel coupled Van der Pol conservative chaotic system and its adaptive control. International Journal of PharmTech Research, 8 (8), (2015), 79-94.

[54] S. VAIDYANATHAN: Global chaos synchronization of Duffing double-well chaotic oscillators via integral sliding mode control. International Journal of ChemTech Research, 8 (11), (2015), 141-151.

[55] S. VAIDYANATHAN and K. RAJAGOPAL: LabVIEW implementation of chaotic masking with adaptively synchronised forced Van der Pol oscillators and its application in real-time image encryption. International Journal of Simulation and Process Modelling, 12 (2), (2017), 165-178.

[56] S. VAIDYANATHAN: Adaptive synchronization of Rikitake two-disk dynamo chaotic systems. International Journal of ChemTech Research, 8 (8), (2015), 100111. 
[57] S. VAIDYANATHAN: Anti-synchronization of Rikitake two-disk dynamo chaotic systems via adaptive control method. International Journal of ChemTech Research, 8 (9), (2015), 393-405.

[58] S. VAIDYANATHAN, C.K. VOLOS and V.T. PHAM: Analysis, control, synchronization and SPICE implementation of a novel 4-D hyperchaotic Rikitake dynamo system without equilibrium. Journal of Engineering Science and Technology Review, 8 (2), (2015), 232-244.

[59] S. VAIDYANATHAN, V.T. PHAM and C.K. VOLOS: A 5-D hyperchaotic Rikitake dynamo system with hidden attractors. European Physical Journal: Special Topics, 224 (8), (2015), 1575-1592.

[60] S. VAIDYANATHAN: Synchronization of Tokamak systems with symmetric and magnetically confined plasma via adaptive control. International Journal of ChemTech Research, 8 (6), (2015), 818-827.

[61] S. VAIDYANATHAN: Dynamics and control of Tokamak system with symmetric and magnetically confined plasma. International Journal of ChemTech Research, $\mathbf{8}$ (6), (2015), 795-803.

[62] S. VAIDYANATHAN: Anti-synchronization of chemical chaotic reactors via adaptive control method. International Journal of ChemTech Research, 8 (8), (2015), 73-85.

[63] S. VAIDYANATHAN: Adaptive control of a chemical chaotic reactor. International Journal of PharmTech Research, 8 (3), (2015), 377-382.

[64] S. VAIDYANATHAN: Global chaos synchronization of chemical chaotic reactors via novel sliding mode control method. International Journal of ChemTech Research, 8 (7), (2015), 209-221.

[65] S. VAIDYANATHAN: A novel chemical chaotic reactor system and its output regulation via integral sliding mode control. International Journal of ChemTech Research, 8 (11), (2015), 669-683.

[66] S. VAIDYANATHAN: Integral sliding mode control design for the global chaos synchronization of identical novel chemical chaotic reactor systems. International Journal of ChemTech Research, 8 (11), (2015), 684-699.

[67] S. VAIDYANATHAN: Adaptive control design for the anti-synchronization of novel 3-D chemical chaotic reactor systems. International Journal of ChemTech Research, 8 (11), (2015), 654-668.

[68] S. VAIDYANATHAN: Adaptive synchronization of chemical chaotic reactors. International Journal of ChemTech Research, 8 (2), (2015), 612-621. 
[69] S. VAIDYANATHAN: A novel chemical reactor system and its adaptive control. International Journal of ChemTech Research, 8 (7), (2015), 146-158.

[70] S. VAIDYANATHAN: Adaptive synchronization of novel 3-D chemical chaotic reactor systems. International Journal of ChemTech Research, 8 (7), (2015), 159171.

[71] S. VAIDYANATHAN: Anti-synchronization of Brusselator chemical reaction systems via adaptive control. International Journal of ChemTech Research, 8 (6), (2015), 759-768.

[72] S. VAIDYATHAN: 3-cells cellular neural network (CNN) attractor and its adaptive biological control. International Journal of PharmTech Research, 8 (4), (2015), 632-640.

[73] S. VAIDYATHAN: Hybrid chaos synchronization of 3-cells cellular neural network attractors via adaptive control method. International Journal of PharmTech Research, 8 (8), (2015), 61-73.

[74] S. VAIDYATHAN: Synchronization of 3-cells cellular neural network (CNN) attractors via adaptive control method. International Journal of PharmTech Research, 8 (5), (2015), 946-955.

[75] S. VAIDYATHAN: Global chaos control of 3-cells cellular neural network attractor via integral sliding mode control. International Journal of PharmTech Research, 8 (8), (2015), 211-221.

[76] S. VAIDYATHAN: Global chaos synchronization of 3-cells cellular neural network attractors via integral sliding mode control. International Journal of PharmTech Research, 8 (8), (2015), 118-130.

[77] S. VAIDYATHAN: Anti-synchronization of 3-cells cellular neural network attractors via adaptive control method. International Journal of PharmTech Research, 8 (7), (2015), 26-38.

[78] S. VAIDYATHAN: Adaptive chaotic synchronization of enzymes-substrates system with ferroelectric behaviour in brain waves. International Journal of PharmTech Research, 8 (5), (2015), 964-973.

[79] S. VAIDYATHAN: Adaptive backstepping control of enzymes-substrates system with ferroelectric behaviour in brain waves. International Journal of PharmTech Research, 8 (2), (2015), 256-261.

[80] S. VAIDYATHAN: Sliding controller design for the global chaos synchronization of enzymes-substrates systems. International Journal of PharmTech Research, 8 (7), (2015), 89-99. 
[81] S. VAIDYATHAN: Anti-synchronization of the FitzHugh-Nagumo chaotic neuron models via adaptive control method. International Journal of PharmTech Research, 8 (7), (2015), 71-83.

[82] S. VAIDYATHAN: Adaptive control of the FitzHugh-Nagumo chaotic neuron model. International Journal of PharmTech Research, 8 (6), (2015), 117-127.

[83] S. VAIDYATHAN: Adaptive synchronization of the identical FitzHugh-Nagumo chaotic neuron models. International Journal of PharmTech Research, 8 (6), (2015), 167-177.

[84] S. VAIDYATHAN: Active control design for the anti-synchronization of LotkaVolterra biological systems with four competitive species. International Journal of PharmTech Research, 8 (7), (2015), 58-70.

[85] S. VAIDYATHAN: Chaos in neurons and adaptive control of Birkhoff-Shaw strange chaotic attractor. International Journal of PharmTech Research, 8 (5), (2015), 956-963.

[86] S. VAIDYATHAN: Global chaos synchronization of the Lotka-Volterra biological systems with four competitive species via active control. International Journal of PharmTech Research, 8 (6), (2015), 206-217.

[87] S. VAIDYATHAN: Active control design for the hybrid chaos synchronization of the Lotka-Volterra biological systems with four competitive species. International Journal of PharmTech Research, 8 (8), (2015), 30-42.

[88] S. VAIDYATHAN: Adaptive biological control of generalized Lotka-Volterra three-species biological system. International Journal of PharmTech Research, 8 (4), (2015), 622-631.

[89] S. VAIDYATHAN: Adaptive synchronization of generalized Lotka-Volterra threespecies biological systems. International Journal of PharmTech Research, 8 (5), (2015), 928-937.

[90] S. VAIDYATHAN: Anti-synchronization of the generalized Lotka-Volterra three-species biological systems via adaptive control. International Journal of PharmTech Research, 8 (8), (2015), 141-156.

[91] S. VAIDYATHAN: Global chaos synchronization of Rucklidge chaotic systems for double convection via sliding mode control. International Journal of ChemTech Research, 8 (8), (2015), 61-72.

[92] S. VAIDYATHAN: Sliding mode control of Rucklidge chaotic system for nonlinear double convection. International Journal of ChemTech Research, 8 (8), (2015), 2535. 
[93] A.E. MATOUK: Chaos, feedback control and synchronization of a fractional-order modified autonomous Van der Pol-Duffing circuit. Communications in Nonlinear Science and Numerical Simulation, 16 (2011), 975-986.

[94] CH.K. VOLOS, I.M. KYPRIANIDIS, I.N. STOUBOULOS and A.N. ANAGNOSTOPOULOS: Experimental study of the dynamic behavior of a double scroll circuit. Journal of Applied Functional Analysis, 4 (2009), 703-711.

[95] CH.K. VOLOS, V.-T. PHAM, S. VAIDYANATHAN, I.M. KYPRIANIDIS and I.N. STOUBOULOS: Synchronization phenomena in coupled Colpitts circuits. Journal of Engineering Science and Technology Review, 8 (2015), 142-151.

[96] K. RAJAGOPAL, S. VAIDYANATHAN, A. KARTHIKEYAN and P. DURAISAMY: Dynamic analysis and chaos suppression in a fractional order brushless DC motor. Electrical Engineering, 97 (2), (2017), 721-733.

[97] CH.K. VOLOS, I.M. KYRPIANIDIS and I.N. STOUBOULOS: Image encryption process based on chaotic synchronization phenomena. Signal Processing, 93 (2013), 1328-1340.

[98] CH.K. VOLOS, I.M. KYRPIANIDIS and I.N. STOUBOULOS: Text encryption scheme realized with a chaotic pseudo-random bit generator. Journal of Engineering Science and Technology Review, 6 (2013), 9-14.

[99] V.-T. PHAM, C. VOLOS, S. JAFARI, X. WANG and S. VAIDYANATHAN: Hidden hyperchaotic attractor in a novel simple memristive neural network. Optoelectronics and Advanced Materials, Rapid Communications, 8 (2014) 1157-1163.

[100] V.-T. PHAM, CH.K. VOLOS, S. VAIDYANATHAN, T.P. LE and V.Y. VU: A memristor-based hyperchaotic system with hidden attractors: Dynamics, synchronization and circuital emulating. Journal of Engineering Science and Technology Review, 8 (2015), 205-214.

[101] CH.K. VOLOS, I.M. KYPRIANIDIS, I.N. STOUBOULOS, E. TLELOCUAUTLE and S. VAIDYANATHAN: Memristor: A new concept in synchronization of coupled neuromorphic circuits. Journal of Engineering Science and Technology Review, 8 (2015), 157-173.

[102] C. VOLOS, I. KYPRIANIDIS, I. STOUBOULOS and S. VAIDYANATHAN: Random bit generator based on non-autonomous chaotic systems. Handbook of Research on Advanced Intelligent Control Engineering and Automation, (2015), 203-229.

[103] P. COULLET, C. TRESSER and A. ARNEODO: A transition to stochasticity for a class of forced oscillators. Physics Letters A, 72 (1979), 268-270. 
[104] J.C. SPROTT: Some simple chaotic jerk functions, American Journal of Physics, 65 (1997), 537-543.

[105] R. LUO and Y. ZENG: The control and synchronization of fractional-order Genesio-Tesi system. Nonlinear Dynamics, 88 (3), (2017), 2111-2121.

[106] A. OUANNAS, A.T. AZAR and S. VAIDYANATHAN: New hybrid synchronisation schemes based on coexistence of various types of synchronisation between master-slave hyperchaotic systems. International Journal of Computer Applications in Technology, 55 (2), (2017), 112-120.

[107] A. OUANNAS, A.T. AZAR and S. VAIDYANATHAN: A robust method for new fractional hybrid chaos synchronization. Mathematical Methods in the Applied Sciences, 40 (2017), 1804-1812.

[108] A. OUANNAS, A.T. AZAR and S. VAIDYANATHAN: On a simple approach for Q-S synchronisation of chaotic dynamical systems in continuous-time. International Journal of Computing Science and Mathematics, 8 (1), (2017), 20-27.

[109] B.A. IDOWU, U.E. VINCENT and A.N. NJAH: Synchronization of chaos in nonidentical parametrically excited systems. Chaos, Solitons and Fractals, 39 (2009), 2322-2331.

[110] S. VAIDYANATHAN and K. RAJAGOPAL: Hybrid synchronization of hyperchaotic Wang-Chen and hyperchaotic lorenz systems by active non-linear control. International Journal of Signal System Control and Engineering Application, 4 (2011), 55-61.

[111] S. VAIDYANATHAN and S. RASAPPAN: Global chaos synchronization of hyperchaotic Bao and $\mathrm{Xu}$ systems by active nonlinear control. Communications in Computer and Information Science, 198 (2011), 10-17.

[112] S. VAIDYANATHAN: Output regulation of the unified chaotic system. Communications in Computer and Information Science, 198 (2011), 1-9.

[113] S. VAIDYANATHAN, A.T. AZAR, K. RAJAGOPAL and P. ALEXANDER: Design and SPICE implementation of a 12-term novel hyperchaotic system and its synchronisation via active control. International Journal of Modelling, Identification and Control, 23 (2015), 267-277.

[114] S. VAIDYANATHAN and S. RASAPPAN: Hybrid synchronization of hyperchaotic Qi and Lü systems by nonlinear control. Communications in Computer and Information Science, 131 (2011), 585-593.

[115] S. PAKIRISWAMY and S. VAIDYANATHAN: Generalized projective synchronization of three-scroll chaotic systems via active control. Lecture Notes of the 
Institute for Computer Sciences, Social-Informatics and Telecommunications Engineering, 85 (2012), 146-155.

[116] V. SUNDARAPANDIAN and R. KARTHIKEYAN: Anti-synchronization of Lü and Pan chaotic systems by adaptive nonlinear control. European Journal of Scientific Research, 64 (2011), 94-106.

[117] V. SUNDARAPANDIAN and R. KARTHIKEYAN: Adaptive antisynchronization of Uncertain Tigan and Li Systems. Journal of Engineering and Applied Sciences, 7 (2012), 45-52.

[118] V. SUNDARAPANDIAN and R. KARTHIKEYAN: Anti-synchronization of hyperchaotic Lorenz and hyperchaotic Chen systems by adaptive control. International Journal of Systems Signal Control and Engineering Application, 4 (2), (2011), 18-25.

[119] P. SARASU and V. SUNDARAPANDIAN: Generalized projective synchronization of three-scroll chaotic systems via adaptive control. European Journal of Scientific Research, 72 (4), (2012), 504-522.

[120] S. VAIDYANATHAN and K. RAJAGOPAL: Global chaos synchronization of hyperchaotic Pang and hyperchaotic Wang systems via adaptive control. International Journal of Soft Computing, 7 (1), (2012), 28-37.

[121] S. VAIDYANATHAN: Hyperchaos, qualitative analysis, control and synchronisation of a ten-term 4-D hyperchaotic system with an exponential nonlinearity and three quadratic nonlinearities. International Journal of Modelling, Identification and Control, 23 (2015), 380-392.

[122] S. VAIDYANATHAN, V.-T. PHAM and C.K. VOLOS: A 5-D hyperchaotic Rikitake dynamo system with hidden attractors. European Physical Journal: Special Topics, 224 (2015), 1575-1592.

[123] P. SARASU and V. SUNDARAPANDIAN: Adaptive controller design for the generalized projective synchronization of 4-scroll systems. International Journal of Systems Signal Control and Engineering Application, 5 (2), (2012), 21-30.

[124] P. SARASU and V. SUNDARAPANDIAN: Generalized projective synchronization of two-scroll systems via adaptive control. International Journal of Soft Computing, 7 (4), (2012), 146-156.

[125] S. VAIDYANATHAN: Adaptive controller and synchronizer design for the QiChen chaotic system. Lecture Notes of the Institute for Computer Sciences, SocialInformatics and Telecommunications Engineering, 85 (2012) 124-133. 
[126] A. OUANNAS, A.T. AZAR and S. VAIDYANATHAN: A new fractional hybrid chaos synchronisation. International Journal of Modelling, Identification and Control, 27 (4), (2017), 314-322.

[127] V.T. PHAM, S. VAIDYANATHAN, C. VOLOS, S. JAFARI and S.T. KINGNI: A no-equilibrium hyperchaotic system with a cubic nonlinear term. Optik, 127 (2016), 3259-3265

[128] S. RASAPPAN and S. VAIDYANATHAN: Synchronization of hyperchaotic Liu system via backstepping control with recursive feedback. Communications in Computer and Information Science, 305 (2012), 212-221.

[129] S. VAIDYANATHAN and S. RASAPPAN: Global chaos synchronization of $n$ scroll Chua circuit and Lur'e system using backstepping control design with recursive feedback. Arabian Journal for Science and Engineering, 39 (2014), 33513364 .

[130] S. VAIDYANATHAN, C.K. VOLOS, K. RAJAGOPAL, I.M. KYPRIANIDIS and I.N. STOUBOULOS: Adaptive backstepping controller design for the antisynchronization of identical WINDMI chaotic systems with unknown parameters and its SPICE implementation. Journal of Engineering Science and Technology Review, 8 (2), (2015), 74-82.

[131] S. VAIDYANATHAN, C. VOLOS, V.T. PHAM and K. MADHAVAN: Analysis, adaptive control and synchronization of a novel 4-D hyperchaotic hyperjerk system and its SPICE implementation. Archives of Control Sciences, 25 (1), (2015), 135158.

[132] S. VAIDYANATHAN, C.K. VOLOS, K. RAJAGOPAL, I.M. KYPRIANIDIS and I.N. STOUBOULS: Adaptive backstepping controller design for the antisynchronization of identical WINDMI chaotic systems with unknown parameters and its SPICE implementation. Journal of Engineering Science and Technology Review, 8 (2), (2015), 74-82.

[133] S. VAIDYANATHAN, B.A. IDOWU and A.T. AZAR: Backstepping controller design for the global chaos synchronization of Sprott's jerk systems. Studies in Computational Intelligence, 581 (2015), 39-58.

[134] S. RASAPPAN and S. VAIDYANATHAN: Global chaos synchronization of WINDMI and Coullet chaotic systems by backstepping control. Far East Journal of Mathematical Sciences, 67 (2), (2012), 265-287.

[135] X. WANG, S. VAIDYANATHAN, C. VOLOS, V.T. PHAM and T. KAPITANIAK: Dynamics, circuit realization, control and synchronization of a hyperchaotic hyperjerk system with coexisting attractors. Nonlinear Dynamics, 89 (3), (2017), 1673-1687. 
[136] S. VAIDYANATHAN and S. SAMPATH: Global chaos synchronization of hyperchaotic Lorenz systems by sliding mode control. Communications in Computer and Information Science, 205 (2011), 156-164.

[137] V. SUNDARAPANDIAN and S. SIVAPERUMAL: Sliding controller design of hybrid synchronization of four-wing chaotic systems. International Journal of Soft Computing, 6 (5), (2011), 224-231.

[138] S. VAIDYANATHAN: Global chaos synchronisation of identical Li-Wu chaotic systems via sliding mode control. International Journal of Modelling, Identification and Control, 22 (2014), 170-177.

[139] S. VAIDYANATHAN and S. SAMPATH: Anti-synchronization of four-wing chaotic systems via sliding mode control. International Journal of Automation and Computing, 9 (3), (2012), 274-279.

[140] S. VAIDYANATHAN: Global chaos control of hyperchaotic Liu system via sliding control method. International Journal of Control Theory and Applications, 5 (2), (2012), 117-123.

[141] S. VAIDYANATHAN, S. SAMPATH and A.T. AZAR: Global chaos synchronisation of identical chaotic systems via novel sliding mode control method and its application to Zhu system. International Journal of Modelling, Identification and Control, 23 (2015), 92-100.

[142] S. VAIDYANATHAN: Analysis and synchronization of the hyperchaotic Yujun systems via sliding mode control. Advances in Intelligent Systems and Computing, 176 (2012), 329-337.

[143] S. VAIDYANATHAN: Anti-synchronisation of identical chaotic systems via novel sliding control and its application to a novel chaotic system. International Journal of Modelling, Identication and Control, 27 (1), (2017), 3-13.

[144] S. VAIDYANATHAN and A. RHIF: A novel four-leaf chaotic system, its control and synchronisation via integral sliding mode control International Journal of Modelling, Identication and Control, 28 (1), (2017), 28-39.

[145] H.K. KHALIL: Nonlinear Systems. New York, Prentice Hall, 2002.

[146] A. WOLF, J.B. SWIFT, H.L. SWINNEY and J.A. VASTANO: Determining Lyapunov exponents from a time series. Physica D, 16 (1985), 285-317. 